\section{Review of the potential use of blood neuro-biomarkers in the diagnosis of mild traumatic brain injury}

\author{
Alastair Jones ${ }^{1}$, Paul Jarvis ${ }^{2}$ \\ 'Department of Emergency Medicine, Bradford Royal Infirmary, Bradford, UK \\ ${ }^{2}$ Global Medical Affairs, Abbott Point of Care, Princeton, NJ, USA
}

Head injury is a common presenting complaint amongst emergency department patients. To date, there has been no widespread utilization of neuro-biomarkers to aid the diagnosis of traumatic brain injury. This review article explores which neuro-biomarkers could be used in the emergency department in aiding the clinical diagnosis of mild traumatic brain injury. Based on the available evidence, the most promising neuro-biomarkers appear to be Glial fibrillary acidic protein (GFAP) and Ubiquitin C-Terminal Hydrolase Isozyme L1 (UCH-L1) as these show significant rises in peripheral blood levels shortly after injury and these have been demonstrated to correlate with long-term clinical outcomes. Treatment strategies for minor traumatic brain inju$\mathrm{ry}$ in the emergency department setting are not well developed. The introduction of blood neurobiomarkers could reduce unnecessary radiation exposure and provide an opportunity to improve the care of this patient group.

Keywords Brain concussion; Biomarkers; Craniocerebral trauma

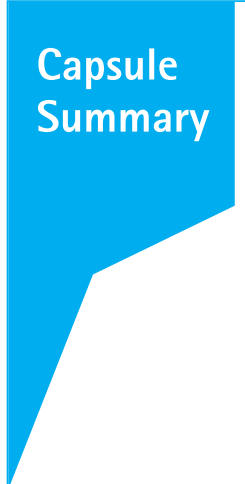

\section{What is already known}

Neuro-biomarkers are not widely used currently to aid the diagnosis of traumatic brain injury in the emergency department.

What is new in the current study

Based on available evidence, the most promising biomarkers which could be used in the emergency department to aid in the diagnosis of traumatic brain injury are ubiquitin C-terminal hydrolase isozyme $L 1$ and glial fibrillary acid protein.
eISSN: 2383-4625

Received: 30 March 2017

Revised: 5 May 2017

Accepted: 29 May 2017

Correspondence to: Alastair Jones Department of Emergency Medicine, Bradford Royal Infirmary, Duckworth Lane, Bradford, West Yorkshire, BD9 6RJ, UK

E-mail: Alastair.Jones@bthft.nhs.uk

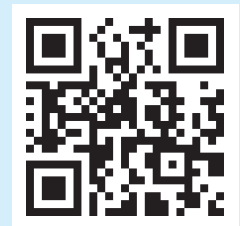

How to cite this article:

Jones $A$, Jarvis $P$. Review of the potential use of blood neuro-biomarkers in the diagnosis of mild traumatic brain injury. Clin Exp Emerg Med 2017;4(3):121-127.

This is an Open Access article distributed under the terms of the Creative Commons Attribution Non-Commercial License (http:// creativecommons.org/licenses/by-nc/4.0/). 


\section{INTRODUCTION}

Traumatic brain injury (TBI) is defined as a traumatically-induced structural brain injury or physiological disruption of brain function caused by an external force. 'Brain injuries can be classified into mild, moderate, and severe categories. Primarily, this classification is based upon the patient's level of consciousness within the first 24 hours. For a patient to be diagnosed with mild TBI (mTBI) they must have normal structural imaging of the brain (such as computed tomography, CT). In addition, patients with mTBI cannot have experienced a period of loss of consciousness for more than 30 minutes, reduced consciousness for more than 24 hours, post-traumatic amnesia lasting more than 24 hours or an initial Glasgow coma score of below 13 in the first 24 hours following a head injury. ${ }^{1}$ Symptoms of mTBI can include headache, nausea, tinnitus, hypersensitivity to light, confusion and other cognitive disturbances.

Head injury is one of the commonest reasons for emergency department (ED) attendance worldwide. Yet, mTBI is often overlooked by clinical teams, as it is not easily identified in the acute setting. The injuries sustained by patients with $\mathrm{mTBI}$ are often seen as "not severe" by clinical staff, who may be falsely reassured by negative CT imaging. Consequently, patients with mTBI are often discharged from the ED with basic written instructions, and little in the way of treatment. However, 15\% of patients with mTBI will experience symptoms for more than one year following injury. ${ }^{2}$ Di Battista et al., ${ }^{3}$ Huang et al., ${ }^{4}$ and Zetterberg and Blennow $^{5}$ have previously reviewed the utility of neuro-biomarkers in assessing patients with TBI. We believe this is the first review looking specifically at the potential utility of neuro-biomarkers in the ED setting.

The assessment of patients with suspected TBI often relies upon neurological imaging such as CT scanning and magnetic resonance imaging (MRI). However, CT has a low sensitivity for $\mathrm{mTBI}$ and exposes the patient to a significant dose of radiation. Conversely, MRI can provide information on the extent of cerebral parenchymal injury, but its availability in the acute setting is limited.

Most patients with mTBI present to the ED for care, but unlike other organ-based diseases, such as myocardial infarction, the clinical utilization of blood biomarkers to facilitate rapid diagnosis and treatment of mTBI is not commonplace. Consequently, the true incidence and characteristics of such patients are not known. ${ }^{6}$

This review article aims to explore which neuro-biomarkers could be used in the ED in aiding the diagnosis of MTBI.

\section{BIOMARKERS}

\section{Astrocyte injury biomarkers}

Astrocytes are characteristic star-shaped, non-neuronal cells that provide support and protection for the neurones of the nervous system. They have many functions, including the provision of biochemical support to the endothelial cells that form the bloodbrain barrier, biochemical and nutrient regulation of the neurones and play a part in repair and scarring processes in the central nervous system following injury. There are two biomarkers that can be used to measure astrocyte injury: $\mathrm{S} 100 \beta$ and glial fibrillary acidic protein.

\section{$S 100 \beta$}

$\mathrm{S} 100 \beta$ is a calcium-binding protein found mainly in the cytosol of astrocytes and Schwann cells. It can also be found in extraneural sites, such as chondrocytes and fat cells. ${ }^{8,9}$ The $S 100 \beta$ protein is eliminated by renal excretion and has a half-life of 30 minutes to 2 hours. $^{10-12}$ Levels are measurable in serum, urine and cerebrospinal fluid. ${ }^{11}$

Several studies have found significant correlation between elevated blood levels of S100 $\beta$ and abnormalities on CT imaging of the brain. ${ }^{13-15}$ Biberthaler et al. ${ }^{14}$ proposed that combining the measurement of $\mathrm{S} 100 \beta$ with a clinical decision-making tool for mTBI could reduce the number of CT scan requests by $30 \%$. However, other investigators have not been able to reproduce this correlation consistently. ${ }^{16-18}$

Elevated serum levels of S100 $\beta$ have been associated with an increased incidence of post-concussion syndrome and transient impairment of cognition following trauma. ${ }^{19,20}$ Other studies have reported that raised serum levels of $\mathrm{S} 100 \beta$ are associated with post-traumatic abnormalities on MRI and with symptomatic neuropsychological disturbances. ${ }^{21,22}$

Elevated levels of $\mathrm{S} 100 \beta$ have also been identified in polytrauma patients without head injuries which raises questions about the specificity of S100 $\beta^{23-26}$ Nygren De Boussard et al. ${ }^{27}$ demonstrated a sensitivity of $\mathrm{S} 100 \beta$ for mTBI when compared with patients with orthopaedic injury without head injury of 61\% (95\% confidence interval, $49 \%$ to $73 \%)$ and a specificity of $77 \%$ (95\% confidence interval, $62 \%$ to $93 \%$ ).

\section{Glial fibrillary acidic protein}

Glial fibrillary acidic protein (GFAP) is an astrocyte structural protein. Vos et al. ${ }^{28}$ demonstrated an association between GFAP levels in patients with severe and moderate TBI and similarly raised levels were associated with adverse outcomes 6 months after injury. In addition, Metting et al. ${ }^{29}$ demonstrated that serum GFAP 
was increased in TBI patients with abnormal CT scans and also demonstrated that GFAP was elevated in patients with axonal injury on MRI three months post injury.

In a study by Papa et al., ${ }^{30}$ GFAP was detectable in serum less than 1 hour after head injury and it was able to reliably distinguish between trauma patients with $\mathrm{mTBI}$ and those without head injury. In this same study, blood GFAP levels were elevated in patients with traumatic intracranial abnormalities on CT compared with those patients without lesions and it could also be used to predict those patients who required neurosurgical intervention.

Papa et al. ${ }^{31}$ directly compared the performance of GFAP with $S 100 \beta$ in a cohort of trauma patients presenting to a level I trauma center. In this study of 397 patients, both GFAP and S100 demonstrated a rapid appearance in serum post-injury with levels detectible within an hour of injury. However, levels of $\mathrm{S} 100 \beta$ were found to be significantly higher in patients with fractures, compared with those who did not, irrespective of whether the patient had a TBI $(P<0.001)$. Conversely, GFAP levels were not affected by the presence of fractures $(P>0.05)$. The area under the receiver operating characteristics curve for predicting traumatic intracranial lesions on $\mathrm{CT}$ for $\mathrm{S} 100 \beta$ was 0.78 (0.67 to 0.89) and GFAP was 0.84 (0.73 to 0.95).

\section{Axonal injury biomarkers}

An axon is a long, willowy projection of a neurone that conducts electrical impulses away from the neuron's cell body. There are three biomarkers that can be used to measure axonal injury: alpha-II spectrin breakdown products (SBDPs), tau proteins, and neurofilaments.

\section{Alpha-II SBDPs}

Alpha-II spectrin is the major structural component of the axonal cytoskeleton. ${ }^{32,33}$ Levels of SBDPs in cerebrospinal fluid have been shown to rise in adults with severe TBI and they have shown a significant relationship with the severity of injury and clinical outcome. ${ }^{32-37}$

Serum SBDPs have been measured in TBI patients and levels were significantly greater in subjects with moderate and severe $\mathrm{TBI}$ than in control patients. ${ }^{38}$ However, this relationship was not demonstrated in patients with $\mathrm{mTBI}$.

\section{Tau proteins}

Tau is an intracellular protein involved with the assembling of axonal microtubule bundles and axonal transport. ${ }^{39}$ Cerebrospinal fluid (CSF) levels of tau protein molecules that have been proteolytically cleaved (c-Tau) are significantly elevated following TBI and these levels correlate with clinical outcome. ${ }^{40,41}$ Unlike CSF,
c-Tau and total tau protein levels in peripheral blood have been shown to be a poor predictor of traumatic lesions on CT and postconcussion syndrome. ${ }^{42-44}$

\section{Neurofilaments}

Neurofilaments are components of the neurone cytoskeleton. Following $\mathrm{TBI}$, calcium influx into the cell triggers a phosphorylation cascade that contributes to axonal injury. ${ }^{45}$ Elevated levels of hyperphosphorylated neurofilaments ( $p-N F)$ have been found in the CSF of patients with severe TBI compared with controls. ${ }^{46}$ Similarly, p-NF levels in venous blood have been shown to correlate with the severity of TBI in children. ${ }^{47}$ Gatson et al. ${ }^{48}$ compared the p-NF serum levels in patients with mTBI and healthy controls. They demonstrated that $\mathrm{mTBI}$ patients exhibited a significant increase in the serum levels of $p-N F$ on days $1(P<0.001)$ and $3(P<0.001)$ following injury and the area under the curve of the receiver operating characteristic curve analysis for $\mathrm{p}-\mathrm{NF}$ in $\mathrm{mTBI}$ was $100 \%$ at both 24 and 72 hours post injury. Early work in animals demonstrated a serum rise in p-NF 6 hours after injury, with levels peaking at 24 to 48 hours before they gradually returned to baseline. ${ }^{49}$ This 6-hour lag between the onset of injury and the rise in blood levels of $\mathrm{p}-\mathrm{NF}$ may limit the usefulness of this biomarker as an aid to diagnosis in the acute setting. However, it may be a useful biomarker when used for prognostic purposes. Anderson et al. ${ }^{49} \mathrm{dem}-$ onstrated that levels measured between 48 to 96 hours post injury may be used to predict patient outcomes.

\section{Neuronal injury biomarkers}

A neurone is a specialized type of cell found within the central and peripheral nervous systems. Neurones are electrically excitable which process and transmit electrical and chemical signals. They interface with adjacent neurones by means of synapses to form neural networks. There are two biomarkers that can be used to measure neuronal injury: neurone specific enolase (NSE) and ubiquitin C-terminal hydrolase isozyme L1 (UCH-L1).

\section{NSE}

NSE is an enzyme found in neuronal cell bodies throughout the nervous system. It is located in other non-neuronal sites, most notably erythrocytes. It has been shown to be elevated after neurone injury. ${ }^{50}$ In patients with severe TBI, blood levels of NSE at 72 hours post injury showed an association with adverse outcomes. $^{51}$

Several reports on blood NSE measurement in patients with mTBI have been published, but most conclude that serum NSE appears to have limited utility as a marker of neuronal injury, ${ }^{50,52-55}$ particularly as hemolysis appears to cause false positive results. ${ }^{56,57}$ 
$U C H-L 1$

UCH-L1 is a protein which is involved in the metabolism of ubiquitin within neurones. ${ }^{58}$ Increases in blood UCH-L1 has been detected in the serum of mild and moderate TBI patients within an hour of injury. ${ }^{59}$ Levels taken within 4 hours of injury were significantly higher in those with TBI lesions on CT than those with a normal intracranial appearance at CT. Blood levels of UCH-L1 have been demonstrated to be able to discriminate between mTBI patients from patients without head injuries and, similar to GFAP, UCH-L1 levels were much higher in patients who required neurosurgical intervention. ${ }^{59}$

Takala et al. ${ }^{60}$ compared serum UCH-L1 and GFAP levels in a prospective trail of 324 patients with TBI. Patients with full recovery and more favourable outcomes (as measured by the Glasgow Outcome Score) had significantly lower UCH-L1 and GFAP levels in the 48 hours immediately following injury.

\section{DISCUSSION}

Until recently, most studies examining neuro-biomarkers had focused on severe TBI. However, as more than $80 \%$ of patients with neurological injury have $\mathrm{mTBI}$ there is a growing need for a rapid and reliable neuro-biomarker test to aid emergency physicians with diagnosis in this patient group. ${ }^{61,62}$

This review identifies a number of neuro-biomarkers which could potentially be used in mainstream clinical practice to facilitate the diagnosis of patients with mTBI. It is our belief that for a neuro-biomarker to be usable in the ED to diagnose mTBI it must fulfil the following criteria: 1) levels must be measurable in peripheral blood shortly after the onset of injury, 2) the test should have sufficient sensitivity to be able to diagnose $\mathrm{mTBI}$, and 3 ) levels are unaffected by non-head trauma.

Based on these criteria, the most promising neuro-biomarkers appear to be GFAP and UCH-L1 as these show significant level rises in peripheral blood shortly after injury and and the levels are unaffected by non-head trauma. Additionally, both have been demonstrated to correlate with long-term clinical outcomes. It appears that GFAP has a consistent ability to detect TBI over the 7 days following injury, whereas UCH-L1 seems to be limited to the early post injury period. ${ }^{63}$

Diaz-Arrastia et al. ${ }^{64}$ recognised that UCH-L1 and GFAP measure separate, distinct molecular events following TBI, and hypothesized that analyzing both biomarkers simultaneously would be superior to studying either biomarker individually. In a cohort of 206 patients with TBI the two biomarkers in isolation had good sensitivity for discriminating between TBI patients and healthy controls (the area under the curve for receiver operator charac- teristic analysis was 0.87 and 0.91 for UCH-L1 and GFAP, respectively). Combining the biomarkers led to superior sensitivity and specificity for diagnosing TBI (area under the curve 0.94)..$^{64}$ This evidence was supported by Papa et al. ${ }^{63}$ who demonstrated that a combination of GFAP and UCH-L1 neuro-biomarkers marginally outperformed GFAP used on its own.

S100 $\beta$ has poor sensitivity and specificity ${ }^{27}$ and is adversely affected by the presence of orthopaedic trauma in the absence of head injury, which is likely to limit its clinical utility in the emergency setting. ${ }^{23-26}$

The utility of NSE in the ED setting is limited by the delay in the rise in peripheral blood levels following injury. ${ }^{51}$ Similarly, $\mathrm{p}-\mathrm{NF}$ has a significant lag from the time of injury to the rise in peripheral blood. ${ }^{49}$ This is likely to limit the usefulness of both of these neuro-biomarkers in the acute diagnosis of mTBI. However, they may become useful prognostic markers in the future.

Although CSF levels of c-Tau protein molecules are significantly elevated following TBI, c-Tau levels in peripheral blood do not correlate with the presence of traumatic lesions on CT. This is likely to limit its usefulness in the diagnosis of $\mathrm{mTBI}$ in the ED. ${ }^{42-44}$ SBDP levels are raised in peripheral blood in moderate and severe $\mathrm{TBI}$, however this relationship has not been reproduced in patients with $\mathrm{mTBI} .^{38}$

Other biomarkers, not specific to the nervous system, such as free DNA, ${ }_{1}^{65}$ interleukins, ${ }_{1}^{66} d$-dimer, ${ }^{67}$ neutrophil gelatinase-associated lipocalin ${ }^{68}$ and cytochrome $\mathrm{C}^{69}$ have been previously studied in the field of brain injury. Despite being outside the scope of this neuro-biomarkers review, we feel that with further development these general biomarkers could potentially be mTBI biomarkers in the future.

\section{CONCLUSION}

Currently, the most promising neuro-biomarkers for use to aid in the diagnosis of $\mathrm{mTBI}$ in the ED are GFAP and UCH-L1 as these are raised in peripheral blood shortly after injury in patients with mTBI and the levels are unaffected by non-head trauma. Utilization of a peripheral blood neuro-biomarker, such as GFAP and UCH-L1, in the ED are likely to facilitate earlier diagnosis of mTBI and potentially reduce the number of $\mathrm{CT}$ scans performed.

\section{CONFLICT OF INTEREST}

Alastair Jones has no conflict of interests. Paul Jarvis is an employee of Abbott Point of Care, which develops and sells diagnostic assays commercially and is presently developing traumatic brain injury assays. 


\section{REFERENCES}

1. O'Neil ME, Carlson K, Storzbach D, et al. Complications of mild traumatic brain injury in veterans and military personnel: a systematic review. Washington, DC: US Department of Veterans Affairs; 2013.

2. Alexander MP. Mild traumatic brain injury: pathophysiology, natural history, and clinical management. Neurology 1995;45: 1253-60.

3. Di Battista AP, Rhind SG, Baker AJ. Application of blood-based biomarkers in human mild traumatic brain injury. Front Neurol 2013;4:44.

4. Huang W, Li SX, Li XJ, Xu HY. Advances in biomarkers of mild traumatic brain injury in cerebrospinal fluid and blood. Fa Yi Xue Za Zhi 2015;31:466-9.

5. Zetterberg $H$, Blennow K. Fluid markers of traumatic brain injury. Mol Cell Neurosci 2015;66:99-102.

6. Baugh CM, Stamm JM, Riley DO, et al. Chronic traumatic encephalopathy: neurodegeneration following repetitive concussive and subconcussive brain trauma. Brain Imaging Behav 2012;6:244-54.

7. Xiong $H$, Liang $W L, W u X R$. Pathophysiological alterations in cultured astrocytes exposed to hypoxia/reoxygenation. Sheng Li Ke Xue Jin Zhan 2000;31:217-21.

8. Zimmer DB, Cornwall EH, Landar A, Song W. The S100 protein family: history, function, and expression. Brain Res Bull 1995; 37:417-29.

9. Olsson B, Zetterberg $H$, Hampel $H$, Blennow K. Biomarkerbased dissection of neurodegenerative diseases. Prog Neurobiol 2011;95:520-34.

10. Egea-Guerrero JJ, Revuelto-Rey J, Murillo-Cabezas F, et al. Accuracy of the $S 100 \beta$ protein as a marker of brain damage in traumatic brain injury. Brain Inj 2012;26:76-82.

11. Rodriguez-Rodriguez A, Egea-Guerrero JJ, Leon-Justel A, et al. Role of S100B protein in urine and serum as an early predictor of mortality after severe traumatic brain injury in adults. Clin Chim Acta 2012;414:228-33.

12. Townend W, Dibble C, Abid K, Vail A, Sherwood R, Lecky F. Rapid elimination of protein $\mathrm{S}-100 \mathrm{~B}$ from serum after minor head trauma. J Neurotrauma 2006;23:149-55.

13. Ingebrigtsen $T$, Romner $B$, Marup-Jensen $S$, et al. The clinical value of serum $\mathrm{S}-100$ protein measurements in minor head injury: a Scandinavian multicentre study. Brain Inj 2000;14: 1047-55.

14. Biberthaler $P$, Linsenmeier U, Pfeifer KJ, et al. Serum S-100B concentration provides additional information fot the indication of computed tomography in patients after minor head injury: a prospective multicenter study. Shock 2006;25:44653.

15. Muller K, Townend W, Biasca N, et al. S100B serum level predicts computed tomography findings after minor head injury. J Trauma 2007;62:1452-6.

16. Phillips JP, Jones HM, Hitchcock R, Adama N, Thompson RJ. Radioimmunoassay of serum creatine kinase $\mathrm{BB}$ as index of brain damage after head injury. Br Med J 1980;281:777-9.

17. Bechtel K, Frasure S, Marshall C, Dziura J, Simpson C. Relationship of serum S100B levels and intracranial injury in children with closed head trauma. Pediatrics 2009;124:e697-704.

18. Piazza 0, Storti MP, Cotena S, et al. S100B is not a reliable prognostic index in paediatric TBI. Pediatr Neurosurg 2007; 43:258-64.

19. Ingebrigtsen T, Romner B. Management of minor head injuries in hospitals in Norway. Acta Neurol Scand 1997;95:51-5.

20. Waterloo K, Ingebrigtsen T, Romner B. Neuropsychological function in patients with increased serum levels of protein S-100 after minor head injury. Acta Neurochir (Wien) 1997; 139:26-31.

21. Ingebrigtsen T, Romner B. Serial S-100 protein serum measurements related to early magnetic resonance imaging after minor head injury. Case report J Neurosurg 1996;85:945-8.

22. Ingebrigtsen $T$, Waterloo $K$, Jacobsen $E A$, Langbakk $B$, Romner B. Traumatic brain damage in minor head injury: relation of serum S-100 protein measurements to magnetic resonance imaging and neurobehavioral outcome. Neurosurgery 1999; 45:468-75.

23. Anderson RE, Hansson LO, Nilsson O, Dijlai-Merzoug R, Settergren G. High serum S100B levels for trauma patients without head injuries. Neurosurgery 2001;48:1255-8.

24. Rothoerl RD, Woertgen C. High serum S100B levels for trauma patients without head injuries. Neurosurgery 2001;49: 1490-1.

25. Pelinka $L E$, Kroepfl $A$, Schmidhammer $R$, et al. Glial fibrillary acidic protein in serum after traumatic brain injury and multiple trauma. J Trauma 2004;57:1006-12.

26. Romner B, Ingebrigtsen T. High serum S100B levels for trauma patients without head injuries. Neurosurgery 2001;49:1490.

27. Nygren De Boussard C, Fredman P, Lundin A, Andersson $K$, Edman G, Borg J. S100 in mild traumatic brain injury. Brain Inj 2004;18:671-83.

28. Vos $P E$, Jacobs $B$, Andriessen TM, et al. GFAP and S100B are biomarkers of traumatic brain injury: an observational cohort study. Neurology 2010;75:1786-93.

29. Metting Z, Wilczak N, Rodiger LA, Schaaf JM, van der Naalt J. GFAP and S100B in the acute phase of mild traumatic brain 
injury. Neurology 2012;78:1428-33.

30. Papa L, Lewis $L M$, Falk JL, et al. Elevated levels of serum glial fibrillary acidic protein breakdown products in mild and moderate traumatic brain injury are associated with intracranial lesions and neurosurgical intervention. Ann Emerg Med 2012; 59:471-83.

31. Papa L, Silvestri S, Brophy GM, et al. GFAP out-performs $S 100 \beta$ in detecting traumatic intracranial lesions on computed tomography in trauma patients with mild traumatic brain injury and those with extracranial lesions. J Neurotrauma 2014;31:1815-22.

32. Goodman SR, Zimmer WE, Clark MB, Zagon IS, Barker JE, Bloom ML. Brain spectrin: of mice and men. Brain Res Bull 1995;36:593-606.

33. Riederer BM, Zagon IS, Goodman SR. Brain spectrin(240/235) and brain spectrin(240/235E): two distinct spectrin subtypes with different locations within mammalian neural cells. J Cell Biol 1986;102:2088-97.

34. Farkas O, Polgar B, Szekeres-Bartho J, Doczi T, Povlishock JT, Buki A. Spectrin breakdown products in the cerebrospinal fluid in severe head injury: preliminary observations. Acta Neurochir (Wien) 2005;147:855-61.

35. Cardali S, Maugeri R. Detection of alphall-spectrin and breakdown products in humans after severe traumatic brain injury. J Neurosurg Sci 2006;50:25-31.

36. Pineda JA, Lewis $S B$, Valadka $A B$, et al. Clinical significance of alphall-spectrin breakdown products in cerebrospinal fluid after severe traumatic brain injury. J Neurotrauma 2007;24: 354-66.

37. Mondello S, Papa L, Buki $A$, et al. Neuronal and glial markers are differently associated with computed tomography findings and outcome in patients with severe traumatic brain injury: a case control study. Crit Care 2011;15:R156.

38. Berger RP, Hayes RL, Richichi R, Beers SR, Wang KK. Serum concentrations of ubiquitin C-terminal hydrolase-L1 and allspectrin breakdown product $145 \mathrm{kDa}$ correlate with outcome after pediatric TBI. J Neurotrauma 2012;29:162-7.

39. Teunissen CE, Dijkstra C, Polman C. Biological markers in CSF and blood for axonal degeneration in multiple sclerosis. Lancet Neurol 2005;4:32-41.

40. Zemlan FP, Jauch EC, Mulchahey JJ, et al. C-tau biomarker of neuronal damage in severe brain injured patients: association with elevated intracranial pressure and clinical outcome. Brain Res 2002;947:131-9.

41. Shaw GJ, Jauch EC, Zemlan FP. Serum cleaved tau protein levels and clinical outcome in adult patients with closed head injury. Ann Emerg Med 2002;39:254-7.
42. Bazarian JJ, Zemlan FP, Mookerjee S, Stigbrand T. Serum S$100 \mathrm{~B}$ and cleaved-tau are poor predictors of long-term outcome after mild traumatic brain injury. Brain Inj 2006;20: 759-65.

43. Ma M, Lindsell CJ, Rosenberry CM, Shaw GJ, Zemlan FP. Serum cleaved tau does not predict postconcussion syndrome after mild traumatic brain injury. Am J Emerg Med 2008;26: 763-8.

44. Ost M, Nylen K, Csajbok L, et al. Initial CSF total tau correlates with 1-year outcome in patients with traumatic brain injury. Neurology 2006;67:1600-4.

45. Buki A, Povlishock JT. All roads lead to disconnection?: traumatic axonal injury revisited. Acta Neurochir (Wien) 2006; 148:181-93.

46. Siman $R$, Toraskar N, Dang A, et al. A panel of neuron-enriched proteins as markers for traumatic brain injury in humans. J Neurotrauma 2009;26:1867-77.

47. Zurek J, Bartlova L, Fedora M. Hyperphosphorylated neurofilament NF-H as a predictor of mortality after brain injury in children. Brain Inj 2011;25:221-6.

48. Gatson JW, Barillas J, Hynan LS, Diaz-Arrastia R, Wolf SE, Minei JP. Detection of neurofilament-H in serum as a diagnostic tool to predict injury severity in patients who have suffered mild traumatic brain injury. J Neurosurg 2014;121:1232-8.

49. Anderson KJ, Scheff SW, Miller KM, et al. The phosphorylated axonal form of the neurofilament subunit NF-H (pNF-H) as a blood biomarker of traumatic brain injury. J Neurotrauma 2008;25:1079-85.

50. Skogseid IM, Nordby HK, Urdal P, Paus E, Lilleaas F. Increased serum creatine kinase BB and neuron specific enolase following head injury indicates brain damage. Acta Neurochir (Wien) 1992;115:106-11.

51. Chabok SY, Moghadam AD, Saneei Z, Amlashi FG, Leili EK, Amiri ZM. Neuron-specific enolase and S100BB as outcome predictors in severe diffuse axonal injury. J Trauma Acute Care Surg 2012;72:1654-7.

52. Ergun R, Bostanci U, Akdemir G, et al. Prognostic value of serum neuron-specific enolase levels after head injury. Neurol Res 1998;20:418-20.

53. Fridriksson T, Kini N, Walsh-Kelly C, Hennes H. Serum neuronspecific enolase as a predictor of intracranial lesions in children with head trauma: a pilot study. Acad Emerg Med 2000; 7:816-20.

54. Ross SA, Cunningham RT, Johnston CF, Rowlands BJ. Neuronspecific enolase as an aid to outcome prediction in head injury. Br J Neurosurg 1996;10:471-6.

55. Yamazaki Y, Yada K, Morii S, Kitahara T, Ohwada T. Diagnostic 
significance of serum neuron-specific enolase and myelin basic protein assay in patients with acute head injury. Surg Neurol 1995;43:267-70.

56. Johnsson $P$, Blomquist $S$, Luhrs $C$, et al. Neuron-specific enolase increases in plasma during and immediately after extracorporeal circulation. Ann Thorac Surg 2000;69:750-4.

57. Ramont L, Thoannes $H$, Volondat A, Chastang F, Millet MC, Maquart FX. Effects of hemolysis and storage condition on neuron-specific enolase (NSE) in cerebrospinal fluid and serum: implications in clinical practice. Clin Chem Lab Med 2005;43:1215-7.

58. Tongaonkar $\mathrm{P}$, Chen L, Lambertson D, Ko B, Madura K. Evidence for an interaction between ubiquitin-conjugating enzymes and the 265 proteasome. Mol Cell Biol 2000;20:46918.

59. Papa L, Lewis LM, Silvestri S, et al. Serum levels of ubiquitin C-terminal hydrolase distinguish mild traumatic brain injury from trauma controls and are elevated in mild and moderate traumatic brain injury patients with intracranial lesions and neurosurgical intervention. J Trauma Acute Care Surg 2012; 72:1335-44.

60. Takala RS, Posti JP, Runtti H, et al. Glial fibrillary acidic protein and ubiquitin c-terminal hydrolase-11 as outcome predictors in traumatic brain injury. World Neurosurg 2016;87:8-20.

61. Consensus Conference. Rehabilitation of persons with traumatic brain injury. NIH Consensus Development Panel on Rehabilitation of Persons with Traumatic Brain Injury. JAMA 1999; 282:974-83.
62. Yealy DM, Hogan DE. Imaging after head trauma. Who needs what? Emerg Med Clin North Am 1991;9:707-17.

63. Papa L, Brophy GM, Welch RD, et al. Time course and diagnostic accuracy of glial and neuronal blood biomarkers GFAP and UCH-L1 in a large cohort of trauma patients with and without mild traumatic brain injury. JAMA Neurol 2016;73: 551-60.

64. Diaz-Arrastia R, Wang KK, Papa L, et al. Acute biomarkers of traumatic brain injury: relationship between plasma levels of ubiquitin C-terminal hydrolase-L1 and glial fibrillary acidic protein. J Neurotrauma 2014;31:19-25.

65. Macher H, Egea-Guerrero JJ, Revuelto-Rey J, et al. Role of early cell-free DNA levels decrease as a predictive marker of fatal outcome after severe traumatic brain injury. Clin Chim Acta 2012;414:12-7.

66. Kossmann $\mathrm{T}$, Hans VH, Imhof HG, et al. Intrathecal and serum interleukin- 6 and the acute-phase response in patients with severe traumatic brain injuries. Shock 1995;4:311-7.

67. Swanson CA, Burns JC, Peterson BM. Low plasma D-dimer concentration predicts the absence of traumatic brain injury in children. J Trauma 2010;68:1072-7.

68. Zhao J, Chen $H$, Zhang M, et al. Early expression of serum neutrophil gelatinase-associated lipocalin (NGAL) is associated with neurological severity immediately after traumatic brain injury. J Neurol Sci 2016;368:392-8.

69. Sullivan PG, Keller JN, Bussen WL, Scheff SW. Cytochrome c release and caspase activation after traumatic brain injury. Brain Res 2002;949:88-96. 